\title{
Homeless university students: Experiences with foyer-type service
}

\author{
Marty Grace \\ Victoria University \\ Deborah Keys \\ Hanover Welfare Services \\ Aaron Hart \\ Victoria University
}

\begin{abstract}
Some young people who have been homeless during their secondary schooling manage to obtain a university place. These young people, and others who become homeless during their university courses, have the opportunity to build a sustainable exit from homelessness through education and support. Very little is known about how many young Australians are in this situation, or what can be done to assist them to complete their degrees. This article reports on research that aimed to document the experiences of 11 university students who had experienced homelessness. The research focussed on the difficulties that these young people faced, and the types of environments and service responses that can make a difference for them. The students were part of a larger study of a foyer-type service. The research found that these young people took longer than the standard duration to complete their degrees. Their study was facilitated by provision of stable, safe accommodation and support when they were acutely homeless, relief from other pressures such as family conflict, protection while maturing, time for overseas born including refugee young people to develop language, skills, and resources, support to heal from past damaging experiences and improve their health, assistance to gain entry to preferred university courses, and pathways into stable housing for the duration of their study.
\end{abstract}

Keywords: youth homelessness; university students; foyers; retention 


\section{Introduction}

Some young people who become homeless during secondary school succeed in obtaining a university place. In addition, some young people become homeless during their university courses. For both of these groups, education provides a potential pathway out of homelessness. These homeless university students are far from the stereotype of street homelessness. They may occasionally sleep rough, but are more likely to be couch surfing, living in overcrowded accommodation, sleeping in cars, or living in accommodation provided by a homelessness service.

Little information exists about the extent of homelessness among university students, or their experiences undertaking university study in such challenging circumstances. Clearly support services have an important role to play in assisting these young people. This article reports on the experiences of 11 young people whose stories were collected as part of a study of the Melbourne Citymission's Step Ahead youth foyer-type service in Melbourne, Australia. The larger study investigated what their time in Step Ahead meant to 29 young people, and the extent to which they were protected against future homelessness, some time after they left the service (Authors, 2011). The research reported in this article aimed to document the experiences of university students who had experienced homelessness. It focussed on the difficulties that these young people faced, and the types of environments and service responses that can make a difference for them.

\section{Context and previous research}

\section{Homelessness}

In Australia, homelessness policy, research and service provision are guided by what has become known as the 'cultural definition' of homelessness. According to this definition, homelessness is understood in relation to community standards and expectations regarding accommodation and living standards. The cultural definition of homelessness refers to primary homelessness (those without conventional accommodation), secondary homelessness (those who regularly move from one form of shelter to another) and tertiary homelessness (those who live in boarding houses on a medium or long term basis) (Chamberlain \& Mackenzie 2008).

There are an estimated 40,000 young Australians affected by homelessness each year (Chamberlain \& MacKenzie, 2009). Employment, education, and training are recognised as playing an important role in young people's pathways out of homelessness (Author, Gronda \& Coventry, 2009; Mission Australia, 2011). In spite of this critical intersection between homelessness and education, we found no published research on university students affected by homelessness before or during their studies. Reasons for this lack of direct attention may be quite complex, and are beyond the 
scope of this article. This review focuses on recent developments in homelessness research, 'youth foyer' model research, and some related research on student poverty.

Past research into homelessness has established that disrupted education, poor employment prospects and homelessness are inextricably linked (Author, Batterham \& Cornell, 2008; Author, Wilson \& Coventry, 2006; MacKenzie \& Chamberlain, 2008; Mallett et al. 2004; Wingert, Higgit \& Ristock, 2005). Internationally, research into homelessness has moved from a focus on factors such as violence, mental illness and addictions associated with homelessness towards looking more at the experiences of people affected by homelessness, as researchers attempt to develop understandings that can assist with prevention, early intervention, service response and service design. In the early 1990s, ground-breaking research into youth homelessness started to explore homeless 'careers', identifying key transitions, for example the permanent break with home and the transition from temporary homelessness to chronic homelessness (Chamberlain \& MacKenzie, 1994).

Recent homelessness research and practice has shifted from the idea of a 'homeless career' to focus on pathways into and out of homelessness (Clapham, 2003). Pathways research is distinctive, bringing together structure and agency, and asking how people get into and sometimes out of difficult situations over time (Anderson \& Tulloch, 2000; Clapham, 2002, 2003; Fitzpatrick,1999; Johnson, Gronda \& Coutts 2008; Mallett, Rosenthal, Keys et al., 2010, May 2000; Morris, Judd \& Kavanagh, 2005; Robinson, 2003).

In Australia, policy and practice interest has turned in recent years to the 'youth foyer' model of assisting homeless young people to engage with employment, education, and training, and to build sustainable pathways out of homelessness. This model offers integrated accommodation and support for up to three years, with a further period of follow-up aftercare, commonly six months.

Foyers in the United Kingdom (UK) were introduced in the early 1990s and modelled on the French system. According to Randolph and Wood (2005) foyers in the UK are typically focused on the needs of 16-25 year-olds who are homeless. They are based on a holistic approach, integrating accommodation, training and job search assistance with services to meet other needs, and based on an individual formal agreement, contract or action plan specifying conditions of continued residence (Lovatt, Whitehead \& Levy-Vroelant 2006).

\section{Student socio-economic status}

There is some evidence that young people affected by homelessness attend university (Author et al., 2011). However, data about how many Australian university students are affected by homelessness has not been collected to date. The most relevant large study was a survey of Australia's 97 universities, with 18,773 responses (AVCC, 2006). It revealed widespread experiences of financial hardship throughout the tertiary student population. with one in eight students indicating that they regularly went without food or other necessities because they could not afford them (AVCC, 2006). Judith Bessant's 
(2003) research into student poverty reported students living in overcrowded and unaffordable housing, and experiencing poor health and wellbeing (Bessant, 2003). Students living in poverty often felt unable to continue study or continue with the course of their preference. The research found that students who had paid work at a level that enabled them to live found their capacity to study was compromised by their employment commitments (Bessant, 2003).

\section{The Step Ahead research}

Step Ahead is a youth foyer-type service operating in Melbourne, Australia since 2004. Recent research followed up 29 ex-residents to find out what their time at Step Ahead meant to them, whether it made any difference in their lives, and how any differences were achieved (Author et al., 2011). The researchers found that Step Ahead assisted young people by offering them suitable, affordable, and safe accommodation at a time when they were homeless and had no other good options. Furnished accommodation with subsidised rent, was provided either in collocated single occupancy apartments in the CBD or in predominantly dual occupancy properties in the inner suburbs. Without Step Ahead, these young people were at risk of making the transition to chronic or street homelessness.

The research found that it was the combination of accommodation and support that enabled young people to pursue their education and employment. The support that made a difference included the flexible, individualised support provided by youth workers, in particular practical assistance such as provision of books and school uniforms, working on personal development, motivation, and supported referral to other services. Aftercare for up to six months following exit is an important feature of the program, although not used by all.

Step Ahead assisted the research participants to pursue their education. At the time of their research interviews, over $80 \%$ had completed year 12 , and $37 \%$ had completed post-school qualifications, including some completion of university degrees. Nearly half were still studying at the time of the research, seven at university and four at TAFE, and four more had plans to commence or recommence post-school education in the near future. The majority of participants advanced their education in the program, and most successfully continued study after they left. However, they struggled to complete their studies within the usually-expected time frames. Support from the Step Ahead program and its workers assisted the participants to overcome the many obstacles they faced. Despite often strong commitment to achieve educationally, young people were faced with structural as well as individual barriers. Without family support, young people's ability to study was hampered by the need to be financially independent, often requiring them to work and study simultaneously (Bessant, 2003). Difficulty securing stable housing had often interrupted study pre-Step Ahead, and also compromised successful educational engagement post-Step Ahead. Nevertheless, some study participants achieved extraordinary outcomes, and most can be described as protected against future homelessness (Author et al., 2011). 
The Step Ahead research indicates that foyer-type services can assist young people who have experienced homelessness to continue their education including completing university degrees. For this article, we extracted the data in relation to the Step Ahead research participants who had some engagement with university, in order to shed some light on their experiences.

\section{Methodology}

The research took an overall interpretivist critical approach: interpretivist because it focussed on the experiences of the young participants, and what those experiences meant to them; critical because of the political intention of the research to contribute to making life better for a disadvantaged group, in this instance homeless young people.

Of the 63 young people who were ex-residents of Step Ahead, 42 were contactable, and of these 29 agreed to participate in the research. A mixed methods multiple case study methodology was utilised. Semi-structured in-depth interviews focussed on how the young person experienced their time with Step Ahead, and what it meant to them, which aspects of the service assisted them, and any suggestions they had for improvements in the service. A questionnaire was used to gather data about accommodation, employment, education and training, health, wellbeing and connection with community. Researchers reviewed the Step Ahead case file for each participant and recorded clients' background at time of entry, supports received, education, employment and training participation and completion, and their situation at time of exit. Data from all sources was combined to create a case study for each participant (as described by Yin 2009). Cross-case quantitative and qualitative analysis was completed (see Author et al., 2011).

The researchers conducted further analysis in relation to the 11 young people who had ever attended university, and this further analysis is reported here. We were looking in particular for anything that could shed light on the commonalities and the diversity of these young people's engagement with university study.

\section{Findings}

This section gives details in relation to the 11 young people who had some involvement with university. As with the broader group of ex-residents of Step Ahead, some were Australian born and some were born overseas, and there was a mixture of young men and young women. Following the details about the group as a whole, we present four vignettes, chosen because they include young people with a range of characteristics and experiences, reflecting the diversity of the sample, and because their experiences illustrate, in context, the themes that are identified in the discussion that follows.

Of the 29 participants in the Step Ahead research, eleven attended university at some stage before, during, or after their time at Step Ahead. They began and concluded their studies at various points in time, as detailed in Table 1. 
Table 1: Participation at various stages

\begin{tabular}{|l|l|}
\hline $\begin{array}{l}\text { Attending University at time of entry into Step } \\
\text { Ahead }\end{array}$ & 1 \\
\hline Commenced university while at Step Ahead & 5 \\
\hline $\begin{array}{l}\text { Commenced university after leaving Step } \\
\text { Ahead }\end{array}$ & 5 \\
\hline Attending university at time of exit & 5 \\
\hline Attending University at time of interview & 7 \\
\hline Discontinued studies prior to completion & 2 \\
\hline $\begin{array}{l}\text { Undertaking postgraduate degree at time of } \\
\text { interview }\end{array}$ & 1 \\
\hline
\end{tabular}

\section{Sample characteristics}

Some of the data reported here was gathered from case files, and not all of these files contained exactly the same information. Thus, the number (n) is different for different variables, depending on whether the data was available for all of the individuals. Six of the 11 young people were female and five were male. Their average age of becoming homeless $(n=9)$ was 17 years and eight months, and the average time spent homeless before entering Step Ahead $(n=9)$ was two years and four months. The average time they spent living in Step Ahead accommodation $(n=11)$ was 21 months. The average age of participants at the time of interview $(n=11)$ was 23 years, with an average time since exiting program accommodation of 2.7 years. At the time of interview, nine of the eleven were current students and two were not. Seven were at university and two who had previously been at university were now at TAFE. Seven of the young people were employed at the time (one full time, four part time, and one casual) and all but one of these were studying as well. Only one participant was neither working nor studying at the time of interview, and she was planning to return to university in the following year. Figure $1(n=11)$ shows the distribution of educational attainment for this group of young people at three points in time - at their point of entry to Step Ahead, their point of exit, and at the time of their interviews for this research. As this figure and the details above show, participation in university education, rather than completion, was the norm for this group. 
Figure 1: Educational attainment at entry, exit and time of interview

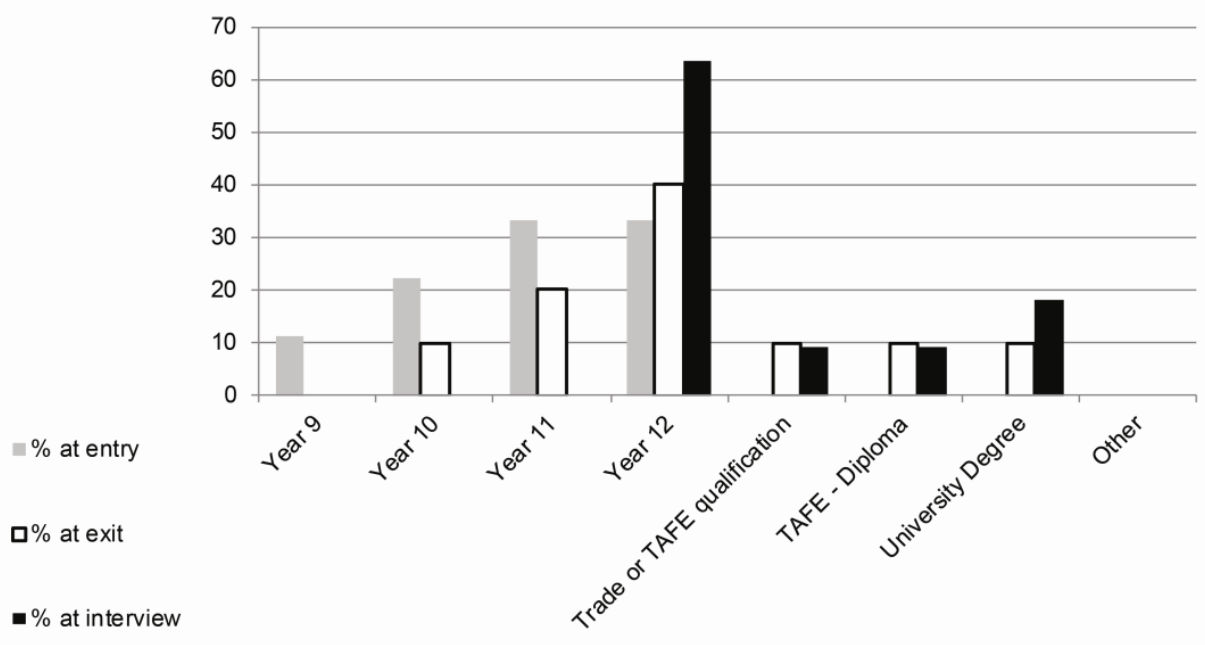

\section{Vignettes}

\section{Ayub}

Ayub was 23 years old when he left his family in Pakistan to study in Melbourne, but soon lost contact with them, due, he believes, to their homophobia. He became homeless after leaving a share house where other residents bullied him. He was enrolled at TAFE in an IT diploma but changed to a building diploma, however homelessness interrupted his study. After three years without secure accommodation, Ayub's case files record that he was suffering from PTSD, depression and anxiety.

Ayub moved into Step Ahead accommodation aged 26. He re-engaged in his building diploma but poor mental health was making full time attendance difficult so he enrolled part time in a building degree. He experienced financial difficulties and was unable to buy shoes or bed clothes. He found part time employment as a kitchen hand and as a taxi driver but was unable to sustain the positions because of study commitments and poor mental health.

After two years with the program, Ayub's mental health was much improved. He moved into subsidised accommodation close to his university, but continued regular contact with his Step Ahead worker for another year. At the time of interview Ayub was doing well at university and living in community housing.

\section{Tara}

Tara entered Step Ahead after exiting foster care, where she had been since age 13 . She was 19 years old and completing her final weeks of year 12. In her application to the program, Tara's DHS worker described her as 'a remarkable young woman who would like to go to Uni next year'. After receiving assistance from Step Ahead to apply for a scholarship, Tara was successful in her application to university.

During Tara's time at Step Ahead, her contact with a family member became problematic, and after 6 months, she ceased attending university. Tara was eventually 
asked to leave Step Ahead for a period of time. She moved into residential substance rehabilitation for a number of weeks. Upon her return to Step Ahead, Tara stopped attending the rehabilitation program, began drinking again, and failed to follow through on employment commitments. She was asked to leave Step Ahead and moved into a crisis refuge 14 months after entering Step Ahead.

At the time of interview, ten months after she left Step Ahead, Tara was living in another supported accommodation program, which she found highly suitable. She was not engaged in employment or studies at the time of interview, but with support intended to re-enter university in the following year.

\section{Nosrat}

After her father died while she was in primary school, Nosrat's family migrated to Australia and left her in their native Iran. She joined them six years later, but became homeless at age 17 after bullying from her sisters. She was 19 years old and completing year 12 when she moved into Step Ahead accommodation. Nosrat stayed in touch with her family and sought assistance from her worker to improve their relationships. While in the program Nosrat was highly motivated in her studies although prone to anxiety and insomnia. She worked regularly at a supermarket and restaurant.

Disappointed with her Year 12 marks, Nosrat was able to negotiate entry into her preferred university course with assistance from her worker. Nosrat moved out of the Step Ahead program after having been there a little over a year. Although Nosrat failed her first year of university, she went on to graduate in Information Technology.

Nosrat now lives with her mother in a small unit and studies education, her second degree. She goes to the gym regularly and keeps in touch with a few close friends.

\section{Vanida}

Vanida left her parents' house in northern Victoria when she was 15 years old. She moved to Melbourne to live with her boyfriend and continued her education. After fifteen months, Vanida found that her lifestyle was interfering with study. She was referred to Step Ahead through her school, and moved into the residence aged 16, while studying year 10 .

During her first year with the program, Vanida led a 'party lifestyle' and was cautioned a number of times regarding her drug use and giving her keys to friends. She eventually found work at a fast food chain, completed year 10, and during her year 11 studies, disassociated from 'partying' peers and became more studious, accessing additional tutoring through Step Ahead. After nearly two and a half years with the program, aged 19, Vanida moved into a community housing property while still at high school. She went on to complete Year 12 and begin her tertiary studies.

Vanida now works part time and studies at university. She is 22 years old and has lived alone for three years in a community housing property. 


\section{Themes}

\section{Stable, safe accommodation and support}

At their time of entry into Step Ahead, all of the young people were provided with safe, stable accommodation at a time when they had no other good options. For most, this meant the difference between progressing their studies or becoming disengaged. The importance of stable accommodation as a platform for other achievements is well recognized (for example, Mallett et al., 2010). Ayub describes what it was like to be without accommodation:

I was one night here, one night there. All day I used to think where I'm going to sleep tonight. Like I was living day by day. Nobody offered me like you can stay for one week. It was like you can stay tonight, you can stay next night as well. You don't know what's going to happen after two days. A couple of times I had nowhere to go. Most of time I spend in the city, in Swanston St. There's a twenty-four hours Macca's so I sit there and watch people. You don't know where you're going to sleep next night so it's like it destroys everything. You can't concentrate, you can't do anything and one night you can stay at the Macca's but next night your body would be exhausted. I had no option. (Ayub)

\section{Support to heal and improve health}

Some of the young people were acutely unwell during their time with Step Ahead and required significant time and support before they were in a position to study. According to Ayub and Sean, both of whom experienced mental illness, the development of a close and supportive relationship was central to their healing. Sean reported that despite all the assistance he had received at Step Ahead and in psychiatric care, it was moving in with and developing the relationship with his brother that had been the most important to his recovery, supporting the findings of other research regarding the unsuitability of foyer-type services for young people with serious mental ill health (Randolph \& Wood 2005).

At a basic level I needed to patch up relations with my brother. It was a turning point to get into a different house with someone that I cared about. (Sean)

Ayub, on the other hand, found that developing a relationship with his Step Ahead worker was most beneficial.

I have like mental problem, it keeps coming and going always and I always need somebody who really supportive that I could talk to. My worker was really understanding, very helpful. She helped me about education matters, about employment, different issues... (Ayub) 
While Nosrat did not suffer major psychiatric problems, she was prone to anxiety and insomnia during her time at Step Ahead. She found that the opportunity to relate to other young people with similar experiences had been helpful.

One of the residents, we kind of had a lot in common and I felt like we could talk and she was going through a similar situation. The staff were really helpful, just the fact that we could talk to each other and we could just be ourselves. (Nosrat)

While each story of connection is unique, the development of trusting and supportive relationships emerged as an important source of healing and stability for participants as they recovered from a period of homelessness.

\section{Relief from other pressures}

The 11 young people included three high achieving students (Giles, Nosrat and Shahla). Step Ahead gave them the opportunity to keep pace with their peers and not be distracted and damaged by prolonged homelessness, important factors in exiting homelessness (Johnson et all, 2008). For these three, education was not delayed. Giles, Nosrat and Shahla were highly committed and engaged with their studies. Despite ongoing conflict with their families, they remained in touch and received some ongoing support; a factor commonly associated with better outcomes (Mallett et al. 2010). These young people are likely to have been delayed and distracted by their lack of accommodation, living skills, income and support without the assistance of a service like Step Ahead.

Giles described what the move to Step Ahead meant for him at the time:

You're forced into a stage of your life you're not quite prepared for. I just had no idea what to do. If I didn't get in the program, it's possible I could have gone off and worked and tried to support myself through high school. I don't think I would have done as well and turned out the same way. Trying to work and support yourself but also dealing with all your demons and personal problems, like I'm safe to say I probably would have burnt out at some point. (Giles)

Nosrat found that being away from a difficult family environment improved her ability to study.

Not being in that situation anymore, not having to fight with my sisters, it was a lot easier. I could actually stay home and study whereas before I didn't want to go home, like if I did go home I couldn't do anything, just wanted to go to bed and sleep and not talk to anyone. (Nosrat) 


\section{Protection while maturing}

When young people spend time homeless, clear identification of aspirations and aptitudes can be delayed by the necessities of survival. Development of the maturity and discipline required to study can also be delayed. Even well supported young people can have a number of false starts before finding a pathway that works for them. This is a vulnerable time, and keeping young people safe from harm while they find their way is essential to enabling successful study in the future. Tara and Zichan both discontinued their studies before completion, but both are likely to return to study with a clearer vision for their future.

Zichan spent 14 months couch surfing after his father was unable to accept his sexual orientation. During his 20 months at Step Ahead, Zichan was able to improve his mental health and complete Year 12 before moving to a regional city to study at a university. He described his subsequent journey as follows:

I was doing a Bachelor of Social Work there but I got really bored of it and stopped. I was working a few odd jobs.

I like social work, I like business, I like front line work so it's hard to decide what I want to study. I've put in VTAC applications just last month. Don't know what I'll get allocated but I'll take whatever that's given this time and run with it.

At work l'm a bit power hungry now. The only way to move on up is to study, get a better position and then use that to change for a better good. I've got a list set up on the wall, l've got these steps, the right steps and the right direction to get there, so education's part of it. (Zichan)

It was nearly four years after leaving Step Ahead before Zichan felt ready to return to university, but the opportunity to clarify his aspirations and priorities has proven valuable. Vanida's story highlights a similar process of moving through stages of maturation before feeling ready to study.

I stopped schooling at the start of year ten and just going from high school to TAFE and VCAL I found it too easy-it felt useless. And I didn't feel like I wanted to go to uni - I just didn't know what I wanted to do. But they helped me with that actually. Like sort of exploring what I wanted to do when I started year eleven and twelve.. When I was sixteen, I had some problems with drugs. It sorted itself out like when I turned I think eighteen, it was all fine. .

I'd done year twelve over two years at TAFE and I think in the first year I sort of wanted to do nursing. (Vanida)

At the time of interview, three years after leaving Step Ahead, Vanida was studying a Bachelor of Arts at university and had some good friends there. 


\section{Time to develop language, skills, and resources}

Around half of the participants in the overall sample, and five of the eleven who attended university, had English as a second language. With complex family histories and the cultural complexities of migration, these young people required time to develop their resources and acclimatise in Australia before university study became possible.

Retta was born in Ethiopia and entered Australia as an asylum seeker at 22 years of age. With no family in Australia, he stayed in a youth refuge for three months after arrival and, with limited English skills, found communication difficult.

I'm coming here as a refugee. I don't have house, I don't know anyone. I can't find study because I don't know where to go.

It's very hard because I'm be in Australia and because I miss my family, everything you know. Because psychological is very important.

When I arrived here, the Melbourne Citymission they help me, they find for me a house and my youth worker she help me with find course. They give me some advice, and some short programs get a drive licence program. They buy for me laptop, just they helping me to study. Encourage to me and to focus with my education and some trainings and to work part time to help myself, to pay my bills. (Retta)

At the time of interview, Retta was continuing his studies and reported very good mental and emotional health. He had a girlfriend and was trying to make more connections within the local community.

\section{Assistance to gain entry}

Because of the multiple disruptions they had suffered, participants had typically achieved lower academic grades than they otherwise may have, limiting their access to preferred courses and institutions. Most universities have access and equity policies that take homelessness and associated forms of disadvantage into account, but participants typically lacked the information and skills to make use of these provisions. Vanida, Sean, Tara, Giles and Nosrat all reported receiving assistance from Step Ahead to apply for scholarships and gain access. For Nosrat, this made all the difference.

The course that I wanted to do was like a scholarship program and you had to have a really high ENTER, and I was under. I was just shattered and one of the youth workers called up, she spoke to them and they said that no, it was fine. I did a few interviews. And we even did like a mock up interview just before, so it really helped. (Nosrat)

Providing extra assistance and resources for young people exiting homelessness to access preferred tertiary options appears important to their success. 


\section{Pathways into stable housing}

As Ayub explained above, successful study without stable housing is bordering on impossible. Fortunately for most participants, Step Ahead was a stepping stone to stable housing. Of the 11 participants who attended university at some stage, four exited Step Ahead into community housing, three moved into private rental, and one found public housing. Others found somewhat less stable accommodation, with two moving into supported or transitional accommodation and one moving back in with parents. Most participants received some assistance from Step Ahead to secure their new accommodation including assisted referrals, and received help to settle in once there. Some participants found the end of their tenure with Step Ahead de-stabilizing, stressful and disruptive to their studies. Participants tended to move properties once every year or so after their departure from Step Ahead, and finding suitable accommodation appeared an ongoing challenge, but no participant became primary, or street homeless. These young people's experiences indicate that the provision of supported housing until they graduate would support the gains made during their time with an intensive service such as Step Ahead.

\section{Conclusion}

Analysis of this small sample provides some insight into the difficulties young people managing university studies and homelessness face and the types of environments and responses that can make a difference. For the 11 young people who attended university in this study, stable, safe accommodation with support, assistance to heal and improve health, relief from other pressures such as family conflict, protection while maturing, time to develop English language proficiency, life skills, and resources, assistance to gain entry to a tertiary institution and the provision of pathways to stable housing were the factors that enabled them to make educational progress. A limitation of the assistance was the housing instability often experienced by participants following their exit from Step Ahead.

The young people's stories illustrate the interplay of structure and agency. The structural disadvantages that led to homelessness were offset by their determination to pursue education and employment. Provision of supported accommodation and practical assistance provided a stable base for building an exit from homelessness. However, the young people's motivation and self discipline was sometimes fragile, and establishing supportive relationships with workers and peers provided much-needed encouragement to sustain the effort required to recover from setbacks. The research reported here provides some insights for both universities and the community-based services that support these young people towards sustainable exits from homelessness. More research with a broader sample is needed to gain greater insight into the needs of young people affected by homelessness as they enter and progress through tertiary education. 


\section{References}

Anderson, I., and Tulloch, D. (2000). Pathways through homelessness: A review of the research evidence. Edinburgh: Homelessness Task Force Series, Scottish Homes.

Australian Vice-Chancellors' Committee. (2006). Australian University Student Finances. Retrieved February 2012, www.avcc.edu.au.

Bessant, J. (2003). The problem of poverty amongst tertiary students: Why it is missing from the policy agenda. Melbourne Studies in Education, Vol 44 (2), 69-87.

Chamberlain, C. \& MacKenzie, D. (2009). Counting the Homeless 2006 (Cat. No. HOU213). Canberra: AlHW.

Chamberlain, C. \& Mackenzie, D. (2008). Counting the homeless: 2006, Australian Census Analytic Program (Cat. No. 2050). Canberra: Australian Bureau of Statistics.

Chamberlain, C. \& MacKenzie, D. (1994). Temporal dimensions of youth homelessness. Australian Journal of Social Issues, vol. 29 (1), 1-25.

Clapham, D. (2003). Pathways approaches to homelessness research. Journal of Community and Applied Social Psychology, vol. 13, 119-127.

Clapham, D. (2002). Housing pathways: a postmodern analytical framework. Housing, Theory and Society, vol. 19 (2), 57-68.

Fitzpatrick, S. (1999). Young homeless people. New York: St Martin's Press.

Authors (2011). Achieving (extra)ordinary aspirations: a research project exploring the role that the Step Ahead program has played in the lives of young people affected by homelessness. Melbourne: Victoria University. Available: http://eprints.vu.edu.au/6831/

Author, M., Gronda, H., \& Coventry, L. (2009). Education, employment and training for young people experiencing homelessness: outcome dimensions. Parity, 22(8), 31-32.

Author, M., Batterham, D. \& Cornell, C. (2008). Multiple disruptions: Circumstances and experiences of young people living with homelessness and unemployment. Just Policy, 48, 23-31.

Author, M., Wilson, N. \& Coventry, L. (2006). Double jeopardy: A socio-demographic profile of homeless jobseekers aged 18-35. Just Policy, no. 40,17-23.

Johnson, G., Gronda, H., \& Coutts, S. (2008). On the outside: pathways in and out of homelessness. North Melbourne: Australian Scholarly Publishing.

Keys, D., Mallett, S., \& Rosenthal, D. (2006). Giving up on drugs: homeless young people and self-reported problematic drug use. Contemporary Drug Problems, 33/Spring, 6398.

Lovatt, R, Whitehead, C and Levy-Vroelant, C 2006, 'Foyers in the UK and France comparisons and contrasts', European Journal of Housing Policy, vol. 6, no. 2, pp. 151-166

Mallett, S., Rosenthal, D., Keys, D. \& Averill, R. (2010). Moving out moving on: Young people's pathways into and through homelessness (Adolescence \& Society Series). UK: Routledge.

Mallett, S., Rosenthal, D., Myers, P., Milburn, N. \& Rotheram-Borus, M. (2004). Practising homelessness: a typology approach to young people's daily routines. Journal of Adolescence, no. 27, 337-349.

May, J. (2000). Housing histories and homeless careers: A biographical approach. Housing Studies, vol. 15(4), 613-638.

Mission Australia. (2011). Addressing Multiple Disadvantage. Sydney: Edith Cowan University, Curtin University, The University of Western Australia, Australian Catholic University, St Vincent De Paul Society, Mission Australia. Retrieved 11 November 2011 from http://www.missionaustralia.com.au/daily-news/3576-catalyst-clementestudy-finds-learning-turns-lives-around 
Morris, A., Judd, B. \& Kavanagh, K. (2005). Marginality amidst plenty: Pathways into homelessness for older Australians. Australian Journal of Social Issues, vol. 40(2), 241-251.

Randolph, B. \& Wood, H. (2005). An interim evaluation of the Miller Live 'N' Learn Campus. Sydney: Australian Housing and Urban Research Institute, UNSW/UWS Research Centre.

Roberts, B. (2002). Biographical research. Buckingham: Open University Press.

Robinson, C. (2003). Understanding iterative homelessness: The case of people with mental disorders. Melbourne: Australian Housing and Urban Research Institute.

Wingert, S., Higgitt, N. \& Ristock, J. (2005). Voices from the margins: understanding street youth in Winnepeg. Canadian Journal of Urban Research, vol 14 (1), 54-80.

\section{Biographical Notes}

Marty Grace is Professor and Head of Social Work in the School of Social Sciences and Psychology at Victoria University, Melbourne, Australia. She undertakes research in the areas of youth homelessness, feminist mothering, and women's creativity.

Dr Deborah Keys is the Homeless Drug Dependency Program Coordinator, Hanover Welfare Services, Melbourne, Australia. She is an experienced researcher in the field of homelessness.

Aaron Hart is a sessional lecturer with the School of Social Sciences and Psychology at Victoria University, Melbourne, Australia, and an experienced researcher and policy worker in the field of homelessness. 